Ines Mergel is assistant professor of public administration and international affairs in the Maxwell School of Citizenship and Public Affairs at Syracuse University. Her research focuses on information management, especially new technology adoption in the field of open government and innovation management in the public sector. E-mail: iamergel@maxwell.syr.edu

Kevin C. Desouza is associate dean for research in the College of Public Programs, associate professor in the School of Public Affairs, and interim director for the Decision Theater in the Office of Knowledge Enterprise Development at Arizona State University. His research interests are in the areas of information and knowledge management, innovation systems, and strategic management of information systems. E-mail: kev.desouza@gmail.com
Syracuse University
Arizona State University

\title{
Implementing Open Innovation in the Public Sector: The Case of Challenge.gov
}

As part of the Open Government Initiative, the Barack Obama administration has called for new forms of collaboration with stakeholders to increase the innovativeness of public service delivery. Federal managers are employing a new policy instrument called Challenge.gov to implement open innovation concepts invented in the private sector to crowdsource solutions from previously untapped problem solvers and to leverage collective intelligence to tackle complex social and technical public management problems. The authors highlight the work conducted by the Office of Citizen Services and Innovative Technologies at the General Services Administration, the administrator of the Challenge.gov platform. Specifically, this Administrative Profile features the work of Tammi Marcoullier, program manager for Challenge.gov, and Karen Trebon, deputy program manager, and their role as change agents who mediate collaborative practices between policy makers and public agencies as they navigate the political and legal environments of their local agencies. The profile provides insights into the implementation process of crowdsourcing solutions for public management problems, as well as lessons learned for designing open innovation processes in the public sector.

If it's a 50\% solution, that's $50 \%$ farther than we got on our own. —Tammi Marcoullier, program manager Challenge.gov

$\mathrm{H}$ ow can a successful private sector practice be introduced in public sector organizations? What are the necessary implementation steps, and how do interorganizational change agents facilitate the implementation process? Here, we focus on the role of two public managers in the General Services Administration (GSA), Tammi Marcoullier and Karen Trebon, who are supporting U.S. federal government agencies in implementing a new policy instrument based on a private sector open innovation approach that incorporates prizes and contests: Challenge. gov.

We first review the existing open innovation literature and discuss the extent to which a successful private sector practice is transferrable to the public sector. We then highlight the organizational barriers that public managers encounter during the implementation process and how managers at GSA help agencies maneuver the organizational change processes. We explain the unique approach used by GSA's program managers to support internal change agents while they explore their organization's environment, relevant legal and political contexts, and evaluate resources and capacities necessary for the successful adoption of an innovative policy instrument. Finally, we provide lessons learned for the implementation of prizes and contests in government in general.

\section{Open Innovation in the Private Sector}

Open innovation encourages organizations to search for solutions outside their organizational boundaries to address core management problems. Chesbrough, Vanhaverbeke, and West define open innovation as "the use of purposive inflows and outflows of knowledge to accelerate internal innovation, and expand the markets for external use of innovation, respectively. [This paradigm] assumes that firms can and should use external ideas as well as internal ideas, and internal and external paths to market, as they look to advance their technology" $(2006,1)$. Open innovation approaches rely on crowdsourcing activities, which Brabham defines as a way to "leverage the collective intelligence of online communities to serve business goals, improve public participation in governance, design products, and solve problems" $(2013,14)$. Instead of relying solely on their own employees, organizations can involve external parties in idea generation, collaborative experimentation, and problemsolving processes (Howe 2006; Surowiecki 2004). Some of the most prominent examples of the use of crowdsourcing approaches are the contributions to Wikipedia and the development of Linux and other open source software (Awazu and Desouza 2004). be leveraged to solve complex problems when resources or expertise are otherwise lacking.
Crowdsourcing approaches allow collective intelligence to 
be leveraged to solve complex problems when resources or expertise are otherwise lacking. Distributed and collective knowledge is harnessed to make sense of large amounts of data. For example, Galaxy Zoo (http://www.galaxyzoo.org/) uses crowdsourcing to engage the public in the identification and classification of galaxies. The public classifies the structure of the galaxies and compares their accuracy against others. In the first year alone, the public completed 50 million galaxy classifications, and accuracy was comparable to the classifications conducted by professional astronomers. The Foldit platform is another example of a successful crowdsourcing effort. Users participate in interactive games to determine the structure of a protein; players are able to view and build on each other's models, leading to a solution in as little as three weeks, when years of medical research had been unsuccessful up to that point (Khatib et al. 2011). Crowdsourcing, while no panacea for organizational innovation, is a powerful approach to tackling complex problems when internal and individualized approaches have not worked.

\section{Open Innovation in the Public Sector}

Implementing open innovation methodologies in the public sector can have myriad positive benefits, including improved awareness of social problems, more effective practices based on broad citizen experience, and increased trust between government and citizens (Bassler et al. 2008; Gaventa and Barrett 2010; Reddel and Woolcock 2004). However, open innovation approaches in the private sector are context dependent- they cannot readily be transferred to the public sector (Louis et al. 2013). Public sector innovation is usually introduced through the policy cycle: a political mandate instructs agencies to expand, abandon, or create a new public service. Based on the political mandate, public agencies then have to respond by implementing the required changes to their service delivery.

Public agencies have rules and regulations that govern their interaction with the public and their ability to source effective solutions. Most of these rules and regulations are based on the traditional mode of contracting (see, e.g., Boyne 1998). Contracting requires agencies to know the solution they need in advance and to work with prescreened vendors. When contending with open innovation, public agencies need to have a greater degree of freedom in sourcing solutions. They need to embrace a much more diverse solution provider space and have limited assurance that the solutions that citizens provide are useful or even implementable. This might have to do with the fact that problem definition occurs under incomplete information and, oftentimes, a limited understanding of how potential solutions can look like. It can also be that solutions from nonprofessional solution providers might not be as substantial as those submitted by professionals and experts. Agencies might have limited capacity to evaluate the innovativeness and appropriateness of the submitted solutions. Agencies are also limited in the type of problems that they can crowdsource through an open innovation process because of their publicness (Bozeman 1987). Public agencies are generally not able to ask outside problem solvers to invent a new business model for government, to reinvent products, or to increase an agency's cost-effectiveness by reducing service delivery to the highest-paying customers (Bozeman and Bretschneider 1994; Perry and Rainey 1988).

The question, therefore, is how can public agencies implement a top-down political mandate within existing standard operating procedures? Fernandez and Rainey (2006) note that formal political mandates do not necessarily result in successful policy implementation. In addition, the extent to which each individual agency adopts the mandate often varies. Every agency faces different internal and external environments that have to be navigated in order to implement a political mandate. Inattention to substantive differences between private and public sector practices may lead to failures in implementing the new policy instrument. Therefore, we investigate the case of Challenge.gov and the role that public managers play in the implementation process when navigating the aforementioned barriers.

\section{The Case: Challenge.gov}

Following the principles of President Barack Obama's Open Government Initiative (White House 2009), the U.S. Office of Management and Budget instructed GSA in an early 2010 memorandum to build a platform called Challenge.gov to support a new policy instrument called "Prizes and Contests" (White House 2010). The guiding principles for the new platform include mechanisms that support the potential (1) to "bring new ideas to the table from unlikely sources" in order to support major breakthroughs on enduring social and technological challenges and (2) to "help address social [needs] in addition to science and technology challenges." The 2010 memo was followed up by the Innovator's Tool Kit, which outlined best practices for the use of prizes and contests and was designed to motivate federal agencies to adopt existing open innovation approaches that had proven successful in the private sector (White House 2012).

Agencies were directed to incorporate new technologies designed to include a diverse range of citizens in the policy-making process. In addition, they were required to find innovative, low-cost solutions to public problems. The Open Government Initiative was based on the notion that including previously disenfranchised stakeholders in problem solving and policy design processes would lead to several positive outcomes, including improved government awareness of social problems, more effective practices based on broad citizen experience, and increased trust between government and citizens.

Challenge.gov was launched by GSA on September 10, 2010, and it has become the dominant platform for federal agencies to host competitions. Challenge.gov is based on ChallengePost.com, which is operated on a no-cost contract basis. It is designed to encourage agencies to increase their capacity to support, design, and manage prizes, whether acting alone or in collaboration with external partners. The goals of Challenge.gov are to (1) help federal agencies launch contests; (2) help the public find, share, and solve contests; and (3) energize innovation in public agencies.

Challenge.gov in the federal government serves as an online platform to host contests, create awareness for unsolved challenges, 
and bring citizens together in a competitive scenario to solve an issue online. The platform is used to drive awareness for unsolved challenges by uniting citizens in a competitive, solution-oriented online environment. Challenges_-or contests_-are novel methods to engage external stakeholders in the problem-solving, solution design, and policy implementation processes (Desouza 2012; Kalil 2006; Mergel 2011). Problem statements further elucidate the challenge issue and call for solutions to address an agency's needs.

Challenges can be designed so that citizens provide solutions but also review and evaluate solutions, vote on solutions, and even get involved in the implementation of solutions and subsequent evaluation of new policies or other types of public sector innovations. The solution providers can be individual citizens, teams of citizens, private or nonprofit organizations, and even industry consortia. Agencies can use this instrument to increase awareness of their mission and value in society by creating open innovation contests that engage the public on salient social challenges and opportunities. With the use of this policy instrument, public agencies can establish a goal without having to preselect the problem-solving approach or team.

As noted earlier, agencies seeking to introduce a successful private sector management approach cannot ignore the systematic differences of the public sector, as well as the specific context in which each agency is embedded (Fernandez and Rainey 2006). Agencies need to evaluate the merits of posting problems openly for a large number of potential problem solvers and weigh this approach against other established innovation acquisition processes, such as requests for proposals or other types of outsourcing to external contractors using a formal contract. When crowdsourcing methodologies are used, it is necessary to develop a plan for implementation, gain support from internal stakeholders (especially top management), allocate appropriate resources in the form of manpower and prize money, and work with legal counsel to design effective structures to integrate the new policy instrument into the existing set of innovation creation processes. Institutionalization of this new tool occurs by adapting the use to the existing legal framework and context of each agency (for an in-depth discussion of how technology innovations such as a Challenge.gov or other social interaction platforms are implemented in the public sector, see Mergel and Bretschneider 2013).

Agencies wishing to host a competition must follow a predetermined process. Each federal agency works with its internal and external stakeholders to identify and scope out public management problems, specifics of potential solutions, the target audience, judging criteria, and the milestones of the contest. The legal governance framework and authority for creating challenges is outlined in the America COMPETES (Creating Opportunities to Meaningfully Promote Excellence in Technology, Education, and Science) Act of 2007. After receiving clearance from their general counsel, agency personnel work with GSA's Office of Citizen Services and Innovative Technologies to upload the competition on the Challege. gov platform. GSA then creates a moderator account that allows personnel from the sponsoring federal agency to manage the details of their competition on the platform. The Office of Citizen Services and Innovative Technologies supports the agency by promoting competitions to the general public through traditional channels, such as press releases, but also by harnessing social media channels.
Table 1 Types of Challenges Posted on Challenge.gov

\begin{tabular}{ll}
\hline Type of challenge & Percentage \\
\hline Science and technology & $40 \%$ \\
Health & $18 \%$ \\
Energy and environment & $12 \%$ \\
Education & $12 \%$ \\
Economy & $9 \%$ \\
Personal and public safety & $6 \%$ \\
Jobs & $4 \%$ \\
International affairs & $1 \%$ \\
\hline
\end{tabular}

At the time of our data collection, 46 agencies had already gone through this internal process to fulfill the requirements of an external political mandate. GSA's program managers have served a critical role in creating a community of practice among the involved public managers and mitigated the risks by sharing already established practices across agencies and providing technical support for the platform itself. In a recent IBM report, Desouza (2012) provides a detailed overview of the current state of Challenge.gov. Of the 179 challenges listed, 110 (61.45 percent) are managed on external platforms (i.e., they were only advertised on Challenge.gov, but submissions, reviews, etc., are handled on alternative sites). Four agencies, including the National Aeronautics and Space Administration, the Department of Health and Human Services, the Environmental Protection Agency, and the U.S. Air Force, have posted 10 or more challenges. Nineteen agencies have posted only one challenge. The U.S. Department of Health and Human Services has sponsored 37 challenges, the most of any agency. Agencies are using this new policy instrument to solicit solutions for a variety of problems (see table 1).

\section{The GSA's Administrators}

Two public managers, Tammi Wark Marcoullier and Karen Trebon, are responsible for GSA's prizes, challenge activities, and services. They manage all aspects of the platform, including training and support for federal agencies that are starting to launch their own contests online.

Marcoullier joined the Office of Citizen Services and Innovative Technologies in May 2011 as the program manager for Challenge. gov. She has a background in journalism and, prior to joining GSA, worked for private sector organizations such as AOL Broadband, Publish2.com, and large national print media organizations such as USA Today and U.S. News \& World Report. Her responsibilities in these organizations included online content creation and launching blogs.

In her role at GSA, Marcoullier designs innovation strategy and leads the community of practice in the U.S. federal government. She also manages the engagement and outreach team at the Center for Excellence in Digital Government. Her areas of program expertise include challenge and prize competitions, social media, multimedia, collaborative applications, and usability assessment. Her team focuses on citizen engagement, effective communications, online strategy, innovation, crowdsourcing, and open government initiatives.

Karen Trebon joined the Office of Citizen Services and Innovative Technologies in 2002. She serves as deputy program manager for Challenge.gov and helped adjust the design and functionalities of the platform as part of her responsibilities at GSA's Center for 
Excellence in Digital Government. Her role includes outreach to help federal agencies and departments adopt the platform in support of their mission. She answers questions and helps other agencies use the site effectively, builds relationships and informs the community of practice, promotes challenges posted by agencies on Challenge. gov through social media channels such as Facebook and Twitter, informs solution providers of upcoming deadlines for submissions, and plans educational events that teach government employees about the importance of challenges and prizes. She catalogs lessons learned and best practices across all challenges and publishes them on How To.gov, a Web site to help government workers deliver improved customer experience to citizens. In addition, Trebon serves as a liaison to the Federal Acquisition Service for the challenge and competition services schedule that GSA has set up. This list of GSAapproved vendors allows public entities to implement challenges with relative ease.

\section{Lessons Learned from Two Years of Challenge.gov}

The introduction of a new platform in combination with new forms of knowledge acquisition and sharing as part of a crowdsourcing process constitutes a departure from standard operating processes for many government agencies. We interviewed Marcoullier and Trebon about the roles they have played as change agents helping public managers interpret the formal political mandate. We also asked them about their experiences in assisting federal agencies design and implement challenges.

Before agencies could upload their first contests to Challenge.gov, managers reported many difficulties navigating their own agency's procedural and legal hurdles. Some initial barriers that they encountered can be traced to the fact that agencies had to understand the implications of this new policy instrument, work through legal constraints where precedence did not exist, and convince stakeholders that it was worth taking the risk to experiment on the new platform. Trebon asserted that it is often beneficial for agencies to hire outside contractors to run challenges on their behalf. Contractors then aid with problem definition, selection and marketing, and analysis of the submitted solutions. Trebon explained,

Vendors are kind of like consultants who can help federal agencies run challenges, if the government person doesn't feel comfortable doing it all by themselves and if they're lucky enough to have funding to hire someone to help them. I try to make recommendations as far as what vendors should be on that schedule and help the government personnel get started on how to use the schedule if they want to.

The publicity of the open innovation platform also was disconcerting for many agencies. Marcoullier noted,

The site is open to the general public at all times. In order to post something here, it is pretty intensive to get your legal departments involved, to get executives to sign-off, or top agency level sign-off. That doesn't stop the experimentation: it just means public managers have to go through a few hoops to get something done. It takes a lot a persistence and patience to make that happen. What we've seen though is that, when people do run a challenge, if they get the results they're looking for, or they learn something from it that's valuable, they'll come back and do it again.

Marcoullier and Trebon provide ongoing support through an online community of practice in which they bring together all managers who have to implement prizes and contests. They provide process support to navigate the administrative hurdles and provide insights into how other agencies have solved legal problems. In addition, they engage in outreach activities to involve agencies that are considering implementing a crowdsourcing solution. GSA representatives meet with the agencies, provide a hands-on introduction to these new policy tools, assist with implementation, and provide ongoing support with challenges. As platform use matures, GSA's program managers also organize insights into higher-level outcomes, such as community building among problem solvers to tap into an established community for future challenges. Through avenues such as GSA's DigitalGov University, administrators are able to bring in external experts to share knowledge and leading practices and even conduct training for the community.

Open innovation approaches are gaining popularity across all levels of government (Mergel 2011). Most approaches can be defined as experimental lighthouse projects, and each case is situated in its own political and legal environment, with a diverse set of unique public management problems. From our interviews with GSA's program managers, we derived five generalizable themes that can help streamline the implementation and adoption process of prizes and contests at other levels of government.

\section{Defining a Successful Challenge Is Not Straightforward}

Initially, public managers tasked with the implementation of contests as a new policy instrument did not have a good sense of how the various dimensions of the challenge would impact outcomes. For example, would challenges offering cash prizes receive more submissions than challenges providing just recognition? Or would prizes that are highly specific in their focus be more popular than those with broader mandates? As a result of this uncertainty, agencies often took a cautious approach when implementing challenges and defining expectations. According to Trebon, "Challenges aren't right for everything. For some agencies, they might want to stick with a grant. Some might want to stick with a traditional procurement.

But we're kind of letting the agencies make that decision in their own house." Uncertainty is further complicated by the fact that running challenges requires agency personnel to evaluate the value added by Challenge.gov versus existing public engagement tools and that this approach invariably incurs additional expenses. As Marcoullier suggested, the use of challenges needs to be evaluated based on "results that meet the mission." Oftentimes, a direct link between a challenge posted to the platform, the actual implementation of the solution, and a valuable outcome is difficult to measure. Nevertheless, most public managers see their participation as an important and contribution to the Open Government Initiative. 
Crowdsourced solutions are often quixotic; solutions might not be readily implementable or may not advance all desired objectives. As discussed later, the lack of clear problem specification on the part of an agency is a primary reason why submitted solutions do not meet expectations. Most public managers do receive valuable contributions for their challenges that help them advance the needle on certain issues and develop deeper insights on problems. Other challenges mostly contribute to an increased public awareness of new policies or programs. The fact that public agencies are opening themselves up to the public is an indicator that they are willing to experiment with innovative tools to improve their decision-making outcomes and are open to more participatory approaches to policy design, implementation, and evaluation.

Up-front, thorough analysis of metrics and outcomes relevant to a specific project is desirable. Public managers should clearly identify key performance indicators necessary for the successful competition of a project. Common success measures include the number of participants, the number and diversity of solutions, the number of solutions from individuals or groups that have not engaged with the agency before, and the level of awareness that a challenge generates. These success measures are especially relevant during the early stages of project implementation, as project success is contingent on securing adequate public engagement. As an agency's experience with crowdsourcing increases, innovative methodologies for the critical evaluation of popular solutions must be created to ensure that each solution generates sufficient value.

\section{Designing Clear Goals for Challenges}

Public agencies have different audiences and goals for their competitions. For example, the U.S. Department of Transportation created a "Connected Vehicles Challenge" to broaden awareness of connected vehicles technology (establishing a network of communication between vehicles) and its role within the research field. Moreover, it targeted students, seeking to engage the next generation of engineers, economists, and others interested in this arena. The Intelligent Transportation Systems Joint Program Office realized that these individuals are the ones coming into the workforce, and therefore being in touch with this technology is essential.

Other agencies sought to find out how data buried in administrative information systems could be leveraged toward the advancement of the agency's mission, greater transparency of operations, or realization of outcomes in an efficient manner. For example, the U.S. Department of Energy's "Apps for Energy” initiative challenges participants to develop innovative applications to reduce energy consumption. The challenge requires participants to use the Green Button data made available by the department, which includes various details regarding the energy consumption patterns of citizens. The challenge also encourages participants to combine these data with other open data available through other U.S. government departments, such as the Census Bureau.

The U.S. Department of Health and Human Services has initiated many challenges aimed at promoting health awareness and hygiene. For example, the "Now Trending: \#Health in My Community" challenge was aimed at

developing innovative tools or techniques to create awareness about health-related issues through social media.

Broadly speaking, challenges can have one or more of the following goals: (1) sourcing specific solutions, (2) enabling the creation of new public resources (e.g., new data repositories), (3) increasing awareness of a social and/or policy issue, and (4) fostering new forms of partnerships in the public sphere (e.g., setting up partnerships between the nonprofit, private, and public sectors). Understanding the goals of a challenge is critical in order to have a successful experience. Too often, managers who have run challenges failed to clearly identify their primary and secondary goals for a challenge. This failure led to a number of negative outcomes: targeting the public with an incorrect message about the challenge's intent, the inability to get attention for solutions received within an agency, and even the inability to assess the success (or failure) of the competition in terms of meeting the objectives. The goals of a challenge need to be explicitly stated, along with the rationale behind them.

\section{Being Precise in Challenge Problem Definition}

A problem definition frames the need for solutions to a given problem, along with specifics, such as how solutions will be evaluated, the design of the submission process, and the overall goal of a challenge from the agency's perspective. Problem definitions are created after the goals of the challenge are clearly delineated-they are more precise and fine-tuned statements. As an example, consider the Cancer Care Video Challenge (http://cancercare.challenge. gov/) run by the Office of the National Coordinator for Health Information Technology in conjunction with the National Cancer Institute, which "invites cancer patients, survivors, and their families and friends to create short, compelling videos sharing a personal story that describes a goal of a cancer patient or survivor, and how technology (such as health IT or consumer eHealth tools) is used to support meeting that goal. There are a variety of tools and applications that can be used to help patients and their families navigate the various aspects of living with or transitioning from cancer treatment to survivorship." Submissions are judged on creativity, potential impact, video and audio quality, and video plays. The overall goal of the challenge is to "generate videos that will inspire and motivate others to become more engaged in their care, through the use of consumer e-health tools and other health IT to improve communication and collaboration with their health care team (doctors, nurses, and other allied health care professionals), and better manage their cancer-related care."

Framing, defining, and writing the problem statement for challenges is one of the most important tasks after the program goals have been clearly delineated. Initial challenges launched on the platform lacked specificity and clarity, which

Surprising to these agencies was the fact that most of the actual solution providers were individuals who already had solutions to the problems being posed and even businesses based on these solutions. led to confusion in terms of expectations. For example, early on, seldom did a challenge specify what kinds of solution providers were eligible to participate. As a result, several agencies expected solution providers to be citizens who would work on the requisite problem in their spare time and who had a passion for the issue. Surprising to these agencies was the fact that most of the actual solution providers were 
individuals who already had solutions to the problems being posed and even businesses based on these solutions. Problem statements should contain rubrics for solution evaluation so that solvers know the targets that they need to achieve in order to be competitive. Problem statements should also contain information on how a solution can be used by a sponsoring agency. Citizens who participate in competitions are enthused by the opportunity to create a solution that actually makes a difference in the public sector (Desouza 2012). Hence, providing more details on the process by which the winning solution will be used by the agency is highly desirable to encourage participation and top-quality submissions.

Marcoullier shared her insights: "Keep your challenge focused on a discrete problem ... That is the key. I think that challenges are not right for solving every problem, but they can be transformative for the right problem. As so defining your problem statement is critical. Being clear about what you are asking people to do, writing it in plain language [is] also critical." Being specific in how a problem is designed ensures that the agency will receive submissions that it can use to advance a cause or make a difference in the life of the public. Simply collecting submissions is not advisable, as it sets the wrong expectations with citizens. Citizens are less likely to participate and invest time in futures challenges if they learn that the agency failed to plan for the implementation of their work.

\section{Attracting Attention and Participation through Incentives}

Identification of appropriate incentives is crucial for ensuring challenge success. This requires agencies to align their expectations with the effort required on the part of citizens to solve the problem as well as the social and economic realities of their target solution providers. Agencies view monetary incentives as a means to incentivize individuals to work on submissions for their challenge. Federal agencies need to attract the kinds of participants who care deeply about the problem statements or can provide expert solutions to the posed problem statements. As Marcoullier noted, "It's knowing what you are asking people to do, knowing what your audience is going to find as a suitable reward. It's not always about the money. Some money is good. Knowing what is appropriate for your solver audience is important." In his interviews with citizens who had won challenges, Desouza (2012) found that receiving financial recognition was of limited interest to the winners. Citizens were more interested in seeing their solutions implemented, expanding their professional networks, and even finding ways to collaborate with agency personnel.

As the number of challenges on the platform increases, it becomes vital for agencies to target their marketing activities so as to compete for attention. As Trebon noted, "Say 8 months ago, had you run a challenge that's all you needed to do. Now challenges are not a novel concept anymore." Today, agencies need to find innovative ways to get their message across, and they are actually competing for attention against other challenges. Some of the ways to gain attention are having notable individuals on judging panels, innovative prizes, larger prize purses, and even media mentions and coverage. GSA helps with expert knowledge and suggests ways to tap into networks of solution providers, target audiences, and use social media to reach out to potential participants. Marcoullier provided an illustrative example:
Another lesson learned is that agencies need to find ways to reach out beyond [their] usual suspects of people you would have solve these problems. I would like to give you an example: A health-related agency wanted to run a video challenge. When we talked to agencies about who they were going to target to submit a video, they wanted to target exactly the same people that they communicate with weekly already as part of their day-to-day operations. . . . We asked them if they would consider marketing the video challenge out beyond that closed known group to students who were studying multimedia, to academic institutions, to people who were in different communities that aren't part of what their familiar circle is.

Desouza (2012) points to another way to increase the awareness and interest in a challenge: the use of an external panel of judges. Challenges that used external judges who had significant notoriety were more popular than challenges that did not have an external panel. Consider the U.S. Department of Commerce's "Business Apps" challenge, which included a judging panel comprising notable people such as Steven VanRoekel (current federal chief information officer), Vint Cerf (vice president and chief Internet evangelist at Google), Vivek Kundra (former federal chief information officer), Tim O'Reilly (founder and chief executive officer of O'Reilly Media), and Sheryl Sandberg (chief operating officer of Facebook). The panel of judges helped spread the word about the competition through the physical and virtual platforms in which they participated (e.g., Twitter, Facebook, etc.).

\section{Building a Community of Practice to Share Lessons Learned}

Lessons learned from each challenge need to be shared across public agencies to ensure that mistakes are not repeated. Our interviews revealed that repetition of mistakes is occurring across various agencies - a dearth of coordination and collaboration is present. No centralized or standardized process for challenge implementation exists; rather, the onus is on the agency to reach out to GSA or the White House. Marcoullier asserted that,
Sometimes they hear about us through colleagues, or they find the Challenge.gov site and they sign up and then come to us with questions. ... They are working on an initiative, and some mention challenges, and some say "Oh, that sounds good." ... So it is a pretty organic the way that people come in and there is no one door, one way they walk in. ... The information does not always filter out of the innovation office down to the ground level of people who are running programs.

A way of mitigating repeated mistakes is to build standardized processes and structures around challenges. For example, every agency refers to its general counsel to determine whether it is within the provisions of the America COMPETES Act. Providing a standardized process can help agencies reduce the amount of time they spend on legalities and allow them to spend more time and resources on the challenge itself. Another benefit of having standardized processes and structures is providing public agencies with a means of identifying common pitfalls and issues, such as having a post-challenge engagement strategy early in the challenge design phase. 
Being able to exchange knowledge such as lessons learned is also critical for Challenge.gov to mature and thrive. An important resource is GSA itself. On its HowTo.gov Web site, the agency provides training material, lessons learned, and success stories for running challenges. DigitalGov University is used as an avenue for peer-to-peer interaction: successful public managers are frequently featured in webinars in combination with solution providers who share their insights and best practices advice. GSA also hosts an e-mail Listserv, frequent phone conferences, online office hours on Google Hangouts, and other information-sharing opportunities to push information out to the community of practice.

\section{Toward Open Innovation Implementation in the Public Sector}

The use of challenges to source innovative solutions to public management problems in the public sector is a new field of inquiry that needs more attention from researchers in public administration. Based on our initial interviews with program managers at GSA and two waves of data collection conducted in 2011 and 2012 with 46 agencies that have started to use contests and prizes as new forms of innovation creation, we developed a set of inquiries for future research. The research agenda outlined here will help advance the field of innovation implementation in public administration, support a deeper understanding how new technologies are adopted, contribute to the process of designing, deploying, and evaluating new policy instruments.

\section{Motivations to Use Contests versus Other Forms of Innovation Acquisition in the Public Sector}

The standard operating procedure for the acquisition of innovations in the public sector is a bureaucratic contracting process that involves specifying a detailed request for proposals, a cumbersome selection process, and messy contract negotiations. While prizes and contests were introduced as a political mandate, agencies face many barriers that prevent them from adopting a crowdsourcing approach to solve their public management problems. Public administration research can contribute to a deeper understanding of the existing barriers as well as the motives for innovation managers in the public sector to depart from the existing innovation acquisition and standard operating procedures and adopt a crowdsourcing approach.

Challenges need to be studied within the ecosystem of other mechanisms that are employed by public agencies to achieve mission objectives. Challenges can be combined with more traditional instruments of contracting. For example, challenges could lead to prizes in which the winners receive the contract to do the work. This would call for changes in how we think of the traditional request-for-proposal process. In addition, challenges could be used to implement policy. Communities could be engaged to compete (and cooperate) on implementing policies in a manner that fits local realities. Prizes could be awarded on the basis of the effectiveness of policy implementation and outcomes (e.g., change in behavior, cost savings, etc.) and various process measures (e.g., transparency, inclusion, etc.).

Today, most of the challenges focus on creating solutions rather than implementing solutions. While generating innovative solutions is important, it is also critical for public managers to find solutions that enable them to implement solutions in an effective and efficient manner. Researchers are well positioned to understand the critical success factors of challenges completed and those in which solutions were actually internalized within the policy process or in the processes of the public agency. Learning from these efforts could lead to a better understanding of the role of challenges in solving the myriad problems and opportunities that public agencies confront. For instance, challenges may not be well suited to problems that need immediate solutions or for which there are strong political divides on proposed approaches to solutions. In addition, challenges may not be suited for problems for which the barriers to creating solutions limit who can participate-for example, in a situation in which the chances of traditional players participating only is high (in this case, a traditional contracting approach may be best).

\section{Redesigning Implementation Processes in Public Institutions to Incorporate Challenges into Current Administrative and Policy Processes}

Public agencies need to adapt their internal processes to take advantage of the crowdsourcing mechanism. Agencies have to go through several internal steps to adapt their existing standard operating procedures and ensure that the new policy instrument fits into the existing legal framework. However, after the initial hurdles are overcome, implementation goes much faster for subsequent contests. As Marcoullier pointed out,

If you look at Department of Labor right now: they started out with a video challenge initially, and then they did some apps challenges, a little bit more aggressive. And once they got those under their belt, they were quicker to launch their next set of challenges, because the time, from seeing some success, and learning the lessons of what you need to do next time, to doing the next one or two or three or four, can increase just exponentially. You don't have to take 6 or 8 months to do the next one. You've already established so much of the groundwork that you can now launch something else within 60 days, and then another 60 days after that, instead of waiting almost a year or half a year to do it.

Not surprisingly, internal adjustments and vetting processes take a long time because of the public character of the platform:

This site is open to the general public at all times. So in order to post something here, it's pretty intensive to get your legal departments involved, to get executives to sign off, or top agency level sign off. I think that doesn't stop the experimentation, it just means they have to go through a few hoops to get something done. And it takes a lot a persistence and patience to make that happen. And, what we've seen though is that, when people do run a challenge, if they get the results they're looking for, or they learn something from it that's valuable, they'll come back and do it again.

Seldom were agencies able to incorporate solutions into their administrative processes or service offerings. One reason for this is that their internal processes were too rigid to account for these solutions. This resulted in limited value appropriation from the challenges. Research is needed to help guide public agencies on viable strategies for modifying and/or extending processes so as to make them amenable to absorbing solutions from challenges. 


\section{Motivations for Citizens to Participate in Open Innovation Contests}

Citizens consider myriad factors beyond just the monetary incentive when they decide to participate in challenges. Some of these factors include testing their development skills, networking with other developers, personal interest in the challenge's domain, exposure to potential app customers, and participation in federal open data projects. Further research needs to focus on understanding the motivational factors that influence a citizen's decision to participate in a challenge. A thorough understanding of motivational factors could help public agencies design improved challenges that encourage greater participation from citizens.

\section{Evaluating the Innovativeness of Solutions}

What are appropriate metrics to evaluate the impact of participating in innovation challenges in the public sector? Public administration researchers can help open the black box and help government understand whether a crowdsourced solution is truly of higher quality than an acquired solution provided by an external vendor. Oftentimes, existing relationships with vendors are the preferred choice of an agency when it comes to problem solving. Can crowdsourced innovations help agencies acquire solutions faster and cheaper or at a higher quality, thus justifying the use of Challenge.gov? How do the solutions compare to internally developed solutions? Research is needed to identify the critical value added of solutions provided by a crowdsourcing approach compared to traditional internal and external sourcing methods.

\section{Design Features for Challenges and the Challenge.gov Platform}

Researchers can conduct experiments to gauge how the presence or absence of various features stimulates or limits participation in the platform. For example, if video capability allows citizens to hear directly from public managers rather than simply reading a challenge description, does this drive participation? Does the presence of a judging panel composed of known experts or celebrities drive participation? Does the presence of an online platform where citizens can share information with the public agency during the ideation process lead to better solutions? These are just some of the questions that we could test experimentally.

\section{Conclusion}

Overall, federal agencies using Challenge.gov as part of the Open Government Initiative have embraced it as an alternative mechanism to sourcing ideas, knowledge, and solutions for the challenges that they face. Citizens have been active participants in the platform, showing that when given an opportunity, citizens will contribute to the advancement of democracy and the vitality of public institutions. Additional scholarly research is needed to understand the contributions of a policy instrument such as Challenge.gov to citizen engagement, innovation creation, and change in the public sector.

\section{Acknowledgments}

We would like to thank Anne Khademian and two anonymous reviewers for feedback that helped us improve the manuscript.

\section{References}

Awazu, Yukika, and Kevin C. Desouza. 2004. Open Knowledge Management: Lessons from the Open Source Revolution. Journal of the American Society for Information Science and Technology 55(11): 1016-19.

Bassler, Allan, Kathy Brasier, Neal Fogle, and Ron Taverno. 2008. Developing Effective Citizen Engagement: A How-To Guide for Community Leaders. Harrisburg: Center for Rural Pennsylvania. http://www.rural.palegislature.us/effective_citizen_ engagement.pdf [accessed September 23, 2013].

Boyne, George A. 1998. Bureaucratic Theory Meets Reality: Public Choice and Service Contracting in U.S. Local Government. Public Administration Review 58(6): 474-84.

Bozeman, Barry. 1987. All Organizations Are Public: Bridging Public and Private Organizational Theories. San Francisco: Jossey-Bass.

Bozeman, Barry, and Stuart I. Bretschneider. 1994. The "Publicness Puzzle" in Organization Theory: A Test of Alternative Explanations of Differences between Public and Private Organizations. Journal of Public Administration Research and Theory 4(2): 197-224.

Brabham, Daren C. 2013. Crowdsourcing. Cambridge, MA: MIT Press.

Chesbrough, Henry, Wim Vanhaverbeke, and Joel West, eds. 2006. Open Innovation: Researching a New Paradigm. Oxford, UK: Oxford University Press. Desouza, Kevin C. 2012. Challenge.gov: Using Competitions and Awards to Spur Innovation. Washington, DC: IBM Center for the Business of Government. http://www.businessofgovernment.org/ report/challengegov-using-competitions-and-awardsspur-innovation [accessed September 23, 2013].

Fernandez, Sergio, and Hal G. Rainey. 2006. Managing Successful Organizational Change. Public Administration Review 66(2): 168-76.

Gaventa, John, and Gregory Barrett. 2010. So What Difference Does It Make? Mapping the Outcomes of Citizen Engagement. Working Paper no. 347, Institute of Development Studies. http://www.ids.ac.uk/idspublication/sowhat-difference-does-it-make-mapping-the-outcomes-of-citizen-engagement 1 [accessed September 23, 2013].

Howe, Jeff P. 2006. The Rise of Crowdsourcing. Wired 14(6). http://www.wired.com/ wired/archive/14.06/crowds.html [accessed September 23, 2013].

Kalil, Thomas. 2006. Prizes for Technological Innovation. Washington, DC: Brookings Institution.

Khatib, Firas, Frank DiMaio, Foldit Contenders Group, Seth Cooper, Maciej Kazmierczyk, and Miroslaw Gilski, et al. 2011. Crystal Structure of a Monomeric Retroviral Protease Solved by Protein Folding Game Players. Nature Structural and Molecular Biology 18(10): 1175-77.

Louis, C., Ines Mergel, Stuart I. Bretschneider, and J. Smith. 2013. Crowdsourcing Policy Innovations Using Challenge.gov. Paper presented at the Public Management Research Conference, Madison, WI, June 20-22.

Mergel, Ines. 2011. Crowdsourced Ideas Make Participating in Government Cool Again. PA Times 34(4): 4, 6.

Mergel, Ines, and Stuart I. Bretschneider. 2013. A Three-Stage Adoption Process For Social Media Use in Government. Public Administration Review 73(3): 390-400.

Perry, James L., and Hal G. Rainey. 1988. The Public-Private Distinction in Organization Theory: A Critique and Research Strategy. Academy of Management Journal 13(2): 182-201.

Reddel, Tim, and Geoff Woolcock. 2004. From Consultation to Participatory Governance? A Critical Review of Citizen Engagement Strategies in Queensland. Australian Journal of Public Administration 63(3): 75-87.

Surowiecki, James. 2004. The Wisdom of Crowds: Why the Many Are Smarter than the Few and How Collective Wisdom Shapes Business, Economies, Societies and Nations. New York: Random House. 
White House. 2009. Memorandum for the Heads of Executive Departments and Agencies, Re: Transparency and Open Government. January 21. http://www. whitehouse.gov/the_press_office/TransparencyandOpenGovernment/ [accessed September 23, 2013].

. 2010. Guidance on the Use of Challenges and Prizes to Promote Open Government. March 8. http://www.whitehouse.gov/omb/assets/ memoranda_2010/m10-11.pdf [accessed September 23, 2013].
2012. Memorandum for the National Science and Technology Council Committee on Technology: Open Innovator's Toolkit. February 8. http:// www.whitehouse.gov/sites/default/files/microsites/ostp/openinnovatortoolkit_ nstcmemo.pdf [accessed September 23, 2013]. 